\title{
Informed Consent in Psychiatric Practice
}

\author{
Dr. C. L. Narayan
}

President, Indian Psychiatric Society, East Zone

\section{ABSTRACT}

All medical interventions need informed consent of the patient, which is obtained after providing all the relevant information to him in a comprehensible form resulting in meaningful decision making. Psychiatric patients, on some occasions, lack the capacity to take decisions on their mental health care and treatment. Utmost care should be taken in dealing with such patients, to proceed for their treatment after obtaining consent from their relatives/friends as per the legal provisions. The recently introduced Mental Health Care Bill - 2013 contains elaborate provisions regarding informed consent, which is to be obtained from persons with mental illness, and/or his nominated representative. Full informed consent is mandatory from all participants before proceeding to carry out any research project. Persons with mental illness who lack capacity to give consent should be included in a research study, only if there is likelihood of benefit for them or if it is intended to promote the health of the population represented by the potential subject.

As I stand here to deliver my Presidential Address before this august gathering, I express my gratitude to all the esteemed members of Indian Psychiatric Society - Eastern Zonal Branch for giving me the honour and opportunity to serve the Society as President. I would like to mention here that I have also had the privilege of serving the Society for four years in the capacity of Honorary Secretary. I would also like to express my thanks and gratitude to my family, teachers and colleagues for their encouragement and support for everything what I have achieved in my life in reaching where I am.

I have selected the topic "Informed Consent in Psychiatric Practice" as the topic of my Presidential Address, as I consider it to be a very important matter for all practising psychiatrists from the medico-legal point of view. As Psychiatry is a branch of Medicine, things applicable in Medicine are also applicable in Psychiatry. A person, who comes for consultation in medical practice, has the following three rights:
- Right to treatment

- Right to information

- Right to confidentiality

The patient coming for consultation has the right to information on all the aspects of his treatment and he accords his consent after considering the information provided to him. Consent is one of the fundamental aspects of medical practice and it has acquired greater importance in recent years as part of legal and ethical issues. Consent as defined in the section 13 of the Indian Contract Act, 1872 is, "Two or more persons are said to consent, when they agree upon the same thing in the same sense". All medical interventions require the consent of the person concerned, barring a few exceptional situations. Any act of medical intervention without consent may be regarded as a criminal act of assault or an act of infringement upon personal autonomy. 
Informed Consent in Psychiatric Practice

The concept of consent is closely linked to the concepts of right and autonomy. The right to consent or to refuse consent to medical treatment is an important right and it has been incorporated into the legal frameworks of almost all democratic countries. ${ }^{1}$ The principle of respect of autonomy is associated with allowing or enabling all to make their own decisions about the health care interventions they will receive. ${ }^{2}$ To make a fully informed decision, he/she must understand all risks and benefits of the procedure and likelihood of success. ${ }^{3}$ The Universal Declaration of Bioethics and Human Rights states "the autonomy of persons to make decisions, while taking responsibility for those decisions and respecting the autonomy of others, is to be respected. For persons who are not capable of exercising autonomy, special measures are to be taken to protect their rights and interests." without the capacity to consent, the Universal Declaration on Bioethics and Human Rights states that "authorization for research and medical practice should be obtained in accordance with the best interest of the person concerned and in accordance with domestic law. However, the person concerned should be involved to the greatest extent possible in the decision making process of consent, as well as that of withdrawing consent" ${ }^{4}$ The World Medical Association International Code of Medical Ethics states that "A physician shall respect a competent patient's right to accept or refuse treatment." ${ }^{5}$ The Supreme Court of India has also stressed the need for informed consent and has observed that " $A$ doctor has to seek and secure the consent of the patient before commencing a 'treatment' (the term 'treatment' includes surgery also). The consent so obtained should be real and valid, which means that: the patient should have the capacity and competence to consent; his consent should be voluntary; and his consent should be on the basis of adequate information concerning the nature of the treatment procedure, so that he knows what is consenting to." 6

Consent is a process of communication between the patient and the physician that results in the patient's authorization or agreement to undergo a specific medical intervention. It is not a routine process of getting a signature of the patient on the consent papers.
Different types of concepts relevant in medical practice are as follows.

$>$ Implied Consent-It is the most common type of consent in vogue in medical consultation. The act of patient coming to the doctor for consultation, advice or treatment and the doctor starting the process of the same is taken to mean that there is implied consent from both sides. But the doctor has a duty to give all related information to the patient.

$>$ Tacit consent - It is the consent expressed silently or passively by act of omission.

$>$ Expressed Consent - It covers all types of consent that are actively expressed by the patient. The expressed consent may be either oral or written. This type of consent is obtained for some specific examination procedures, major diagnostic procedures, general anaesthesia, surgical operation etc.

$>$ Informed Consent - Informed consent is, in most cases, the ideal form of consent because it includes all aspects of meaningful decisionmaking. ${ }^{1}$ It is the consent given voluntarily by a competent individual who has received the necessary information, has adequately understood the information and after considering the information, has arrived at a decision without having been subjected to coercion, undue influence or inducement, or intimidation. It is a process of communication between a patient and physician that results in the patient's authorization or agreement to undergo a specific medical intervention.

$>$ Proxy Consent - It is the consent obtained from persons other than the patient himself. If the patient is a minor, consent is obtained from his parents, guardian or attendants. In case of unconscious patients who are not in position to accord their consent, consent is obtained from the immediately available relative or attendant. Similarly, in case of persons with mental illness (PMI) who lack capacity to make mental health care and treatment decisions, consent is obtained from relatives or friends. 


\section{Informed Consent in Psychiatric Practice}

$>$ Presumed Consent - It is applicable in cases of emergencies, when none is present to consent on behalf of the patient. It is based on general theory of human goodwill and rationality.

Times have substantially changed since those when doctors were held in high esteem. Nowadays, medical professionals are frequently slapped with litigation in course of their practice. Keeping this in view, it has become increasingly necessary to get written expressed and informed consent even for minor medical procedures or for psychotherapeutic procedures other than routine procedures of consultation. Recording consent is also necessary in any research project.

\section{INFORMED CONSENT}

Consent has three components. It must be

- Informed

- Voluntary and

- Competent $^{7}$

Apart from the communication of information, it also involves the act of consenting.

Informed Consent, as defined in the Mental Health Care Bill, 2013 means "consent given to a proposed specific intervention, without any force, undue influence, fraud, threat, mistake or misrepresentation, and obtained after disclosing to the person adequate information including risks and benefits of, and alternatives to, the proposed intervention in a language and manner understood by the person". ${ }^{8}$

ICMR defines informed consent as "consent given voluntarily by a competent individual who has received necessary information, has adequately understood the information and after considering the information, has arrived at a decision without having been subjected to coercion, undue influence or inducement or intimidation". 9

Five steps involved in informed consent are as follows : ${ }^{3}$
- Voluntarism

- Capacity

- Disclosure

- Understanding

\section{DECISION}

Voluntarism denotes patient taking the decision on his own without any fraud or pressure. Capacity to take decision and understanding about the information provided by the physician is relevant in case of PMI. It is the physician's duty to provide the relevant information on the basis of which the patient takes the decision.

Things to be disclosed in order to obtain informed consent are :

$>$ The patient's diagnosis, if known;

$>$ The nature and purpose of a proposed treatment or procedure;

$>$ The risks and benefits of a proposed treatment or procedure;

$>$ Alternatives (regardless of their cost or the extent to which the treatment options are covered by health insurance);

$>$ The risks and benefits of the alternative treatment or procedure; and

$>$ The risks and benefits of not receiving or undergoing a treatment or procedure.

All these things are to be disclosed to the patient in a language and manner understood by the person. It is ideal that the doctor himself provides all the information to the person. If the person does not know the language in which information is given, an interpreter has to be engaged and his signature should be taken as a witness. The person should get an opportunity to ask questions to have a better understanding of the treatment or procedure, so that he or she can make an informed decision to proceed or to refuse a particular course of medical intervention. Patients respond better and feel more confident if various issues and options are discussed 
in detail. Taking informed consent is a continuing process and fresh informed consent is required if any new development or change in treatment plan has occurred. The concept of informed consent in psychiatry is applicable to a variety of issues, ranging from consultation, psychological tests, treatment, ECT, TMS or other similar types of treatment and psychotherapeutic procedures. In research projects taking written informed consent of the patients is mandatory.

However, there are some exceptions to the rule of informed consent, which are as follows.

$>$ Emergency situation - If the patient is unconscious and there is no one to accord consent on behalf of the patient, doctors can proceed on the basis of presumed consent and in the best interest of the person. But there are some situations in which controversies may arise. For example people belonging to the faith of Jehovah witnesses do not accept blood transfusion in any situation.

$>$ Judicial orders - If someone is being examined on the basis of a judicial order, the consent of the person is not necessary. The judicial order is a substitute for the consent and the person being examined is supposed to comply with the order.

In case of certain mental illnesses, a PMI may not have the mental capacity to make an informed choice. In such situations, we can proceed with the examination and treatment after taking consent from his/her relatives or friends (proxy consent).

\section{INFORMED CONSENT IN PMI}

Informed consent acquires special importance in psychiatry because in some cases the PMI may not have the capacity to make mental health care and treatment decision. It must be remembered that the lack of capacity to take decision involves a small minority of PMI. Approximately, less than $2-3 \%$ of the PMI may have impairment in decision making capacity for a particular situation. ${ }^{10}$ Moreover, any
PMI should be assumed to have the capacity unless it is established that he lacks the capacity. Therefore, in all such cases where the PMI is an adult and possesses the capacity to make the concerned decision, the psychiatrist must obtain the informed consent from the patient himself by providing him/her all the relevant information and helping him/her to take decision. The information is to be given to the person in a simple language which he understands or in a sign language or by using visual aids or any other means to enable him to understand the information.

A PMI is considered incapable of giving informed consent owing to mental disorder, if the mental disorder prevents him from

- Understanding what he is consenting to

- Choosing decisively

- Communicating his/her consent

- Accepting the need for a medical intervention ${ }^{11}$ The abilities that most consistently appear to be relevant to patients' capacity to make logical decisions regarding treatment fall into the following categories:

- Ability to understand relevant information

- Ability to retain, make and communicate choices

- Ability to appreciate the situation and its likely consequences.

- Ability to manipulate information rationally ${ }^{10}$

Mental disorders often prevent patients from understanding the nature and purpose of a medical intervention, and may also prevent patients from choosing decisively. They may also interfere in patients' communicating their consent. It should be kept in mind that it is not a static but a dynamic phenomenon. It is not an all-or-none phenomenon, but specific to the situation and task. ${ }^{10}$ Severity of mental illness is also an important aspect that affects the capacity. In case of PMI who are not having the 
capacity, autonomy can be overridden on grounds of incapacity to make treatment decisions. In such cases, family members or their legal guardian become substitute decision makers and patients may be treated without their consent. ${ }^{10}$

\section{ASSESSMENT OF CAPACITY TO TAKE MENTAL HEALTH CARE AND TREATMENT DECISIONS}

Assessment of competence includes evaluation of the person's ability to :

$>$ Communicate choices

$>$ Understand relevant information in relation to the project

$>$ Appreciate one's situation and the consequences

$>$ Manipulate information rationally ${ }^{12}$

The MHA- $1987^{13}$ does not have definition of the capacity in case of PMI. But the MHC Bill -2013 defines it as "the capacity to make mental health care and treatment decisions" and says that every person, including a person with mental illness shall be deemed to have capacity to make decisions regarding his mental health care or treatment decision, if such person has ability to :

a. understand the information relevant to the mental health care or treatment decision;

b. retain that information;

c. use or weigh that information as a part of the process of making the mental health care or treatment decisions; and

d. communicate his decision by any means (including talking, using sign language or any other means). ${ }^{8}$

Persons lacking the above mentioned capabilities would be deemed to be lacking the capacity to make mental health care and treatment decisions. When a person has made a decision regarding his mental care and treatment, and the decision is perceived as wrong or inappropriate, this by itself would not mean that the person does not have the capacity to take mental health care and treatment decisions. In situations where the PMI ceases to have the capacity to take mental health care and treatment decision, the informed consent has to be obtained from his relatives/friends/nominated representative. Full written documentation in all such cases is strongly advised before starting treatment, after recording the name, identification details and the relationship with the patient. The specific reason for obtaining the proxy consent should also be recorded.

Applebaum and Grisso, $2001^{14}$ has devised an assessment tool for clinical research, known as MacArthur Competence Assessment Tool for clinical research (MacCAT-CR), which has become one of the most widely used tools for the purpose. It assesses competence on four subscales:

$>$ Understanding information

$>$ Appreciation of the significance of the information

$>$ Reasoning with the information

$>$ Expressing a choice

Decisional capacity depends on the particular context and there is no particular level of ability to determine adequate capacity in all circumstances and there is no established cut-score or algorithm for categorical determination of capacity or incapacity. Therefore, its scores should generally be supplemented with other important information such as mental status examination and decision making context. Moreover, this scale has not been adequately validated in the Indian context. ${ }^{15}$

\section{INFORMED CONSENT UNDER MHA-1987 AND MHC BILL, 2013}

The Mental Health Act, 1987 (MHA-87) defined mentally ill person simply as "a person who is in need of treatment by reason of any mental disorder other than mental retardation". There is no specific mention of informed consent except in relation to the purpose 
of research under section $81(2)$, which is discussed below. Section 19 of the MHA implies proxy consent under the provision of Admission under special circumstances. Here, the relative or friend has to apply on behalf of the mentally ill person, who does not, or is unable, to express his consent. According to the procedure as described, if it is certified that the condition of such mentally ill person is such that he should be kept under observation and treatment as an inpatient in a psychiatric hospital or psychiatric nursing home.

In the MHC Bill, 2013, informed consent finds mention at several places. The Bill has defined both informed consent and the capacity to make mental health care and treatment decisions which are described as above. If the patient lacks the capacity to make mental health care and treatment decision, informed consent is to be obtained from his nominated representative, as defined in the section 14 of the Bill. Every person, who is not a minor, has the right to appoint a nominated representative, who shall be competent to discharge the duties or perform function as assigned in the Bill. When no nominated representative has been appointed, persons to be deemed as nominated representative in order of preference are given. PMI may require varying level of support from their nominated representative to make decisions. In case of minors, the legal guardians are to be their legal guardian, unless the concerned Board orders otherwise. Nominated representative appointed as provided, shall provide support to the PMI in making treatment decisions under sec 98 \& 99 (supported admission).

Section 95 of the MHCB provides for independent admission and it also provides that all treatment of such patients shall not be given treatment without taking informed consent. Similarly for minor patients, informed consent has to be obtained from the legal guardian (sec 96). Every person, admitted under sections $98 \& 99$, are to be provided treatment after taking into account the advanced directive or informed consent of the patient with the support of his nominated representative. Current and past wishes, values, interests, cultural background, views of the PMI to the extent he understands are to be kept in consideration. Patients or his nominated representative have the right to seek information on diagnosis and treatment.

Under the sec 22 of the MHCB - 2013, all PMI and / or his nominated representative have the right to know the provision of the Act or any other law for the time being in force under which he has been admitted and the fact that he has right to make an application to the concerned Board for a review of his admission. The PMI and his nominated representative have also the right to information about the nature of the person's mental illness and the proposed treatment plan and the known side effects of the proposed treatment. In case complete information cannot be given to the PMI, it has to be given to his nominated representative. If the information has not been given to the PMI at the time of admission or at the start of the treatment, the medical officer or the psychiatrist has the duty to provide the full information promptly when the individual is in a position to receive it.

The MHCB - 2013 has also introduced a concept of 'advance directive' and it provides that every person, who is not a minor, has the right to make an advance directive in writing, specifying the way the person wishes to be cared for and treated for or not to be cared for and treated for a mental illness. He also have a right to specify the individual or individuals, in order of preference, he wants to appoint as his nominated representative. The advance directive is to be registered with the Mental Health Review Board and is to be invoked when the person ceases to have the capacity to make mental health care and treatment decision. The psychiatrist in charge of treatment of the PMI is duty-bound to follow the advance directive executed by the PMI. The person writing the advance directive and his nominated representative have a duty to ensure that the mental health professional or the medical practitioner has the access to the advance directive when required. Advance directive is not applicable under the emergency treatment provisions under the MHCB. 
Application to modify, alter or cancel the advance directive can be made to the Mental Health Review Board.

\section{INFORMED CONSENT IN PSYCHIATRIC RESEARCH}

Section 81(2) of MHA-1987 states that "no mentally ill person under treatment shall be used for purposes of research, unless - such person, being a voluntary patient, has given his consent in writing or where such person (whether or not a voluntary patient) is incompetent, by reasons of minority or otherwise, to give valid consent, the guardian or other person competent to give consent on his behalf, has given his consent in writing, for such research". Under the section 108 of the MHCB-2013, free and informed consent has to be obtained from all the PMIs involved in any research projects. In case of persons unable to give free and informed consent, permission has to be obtained from the State Mental Health Authority. The Authority may allow the research to proceed based on informed consent being obtained from the nominated representative of the PMI.

Thus, full informed and written consent is necessary from all the participants in any type of research studies. In case of minors, proxy consent has to be obtained from parents/responsible guardian and in addition minor's assent should also be obtained and recorded. A witness is necessary in case of illiterate participants. Written documentation on prescribed consent forms (approved by Institutional Review Board or Independent Ethics Committee) with dated signatures is necessary and has to be obtained prior to start of the research activity. Taking informed consent is a communication process between the researcher and the participant and does not merely consist of a signature on the consent form. ${ }^{15}$ All the pertinent aspects of the study including the details and purpose of the study are to be discussed. All the queries/doubts of the participants are to be cleared. A written information sheet containing all information in simple, non-technical language understandable by the patient should be given to the participant to keep. The Indian Council of Medical Research (ICMR) in schedule Y of its Ethical Guidelines for Biomedical Research, 2006 carries elaborate guidelines and describes detail elements of informed consent in Biomedical Research. ${ }^{4}$

If the participant does not have capacity/ competence to accord valid informed consent, the proxy consent has to be obtained from a responsible family member/guardian. Formal assessment of competence to consent to research may be necessary in those subjects where the research involves more than minimal risk.

ICMR stipulates the requirement of fresh or reconsent in situations where participation was under proxy consent and now the participant has regained the capacity to consent. Fresh or re-consent is also necessary on availability of new information, substantial change in protocols, treatment modality or site visits or where long term follow-up is planned later.

World Medical Association (WMA) Declaration of Helsink $\mathrm{i}^{16}$ stipulates that persons with psychiatric disorders who lack capacity to consent should be included in a research study only if there is likelihood of benefit for them or it is intended to promote the health of the population represented by the potential subject and the research cannot be instead performed with competent persons and the research entails minimal risk and minimal burden. In addition to the consent from the legally authorized representative, the physician must seek assent of the incapacitated participant and potential subject's dissent should be respected.

\section{COVERT MEDICATION}

Covert medication is practice of hiding medications in food and beverages so that it goes undetected. It is used in patients who are not in position to accord consent or refuse consent due to lack of insight. The practice of covert medications is applied in two different types of settings. 
Informed Consent in Psychiatric Practice

1. Long term care patients of dementia or similar illnesses, where medicines are given to control behavioral symptoms who refuse to take medications on their own; or in patients of mental sub-normality who have behavioral symptoms.

2. In context of patients of schizophrenia, delusional disorder or bipolar disorder who refuse to take medications, because they think they do not need it. ${ }^{17}$

Although covert medication is not commonly described in psychiatric literature, it is, nevertheless, more common than one might imagine. ${ }^{18}$ The medications are given without the informed consent of the patient, though it is with the consent from their relatives/friends. The practice of covert medication, though widely prevalent, is questionable both ethically and legally. The practice is clearly illegal in most of the countries and deemed to be unethical by most of the professional societies. Though Royal College of Psychiatrists has guidelines "College Statement on Covert Administration of Medicines", the statement itself stipulates that it allows covert medications only in severely incapacitated like those suffering from advanced dementia, delirium and severe mental retardation with behavioral symptoms. ${ }^{19}$ In western societies, emphasis is more on rights and autonomy of the patients. Therefore, covert medications are not generally acceptable and stern actions are taken whenever it is detected. But in eastern societies, in contrast, the family is a strong unit and the rights of the individual tend to be subsumed by the family. ${ }^{20}$ Therefore, the use of covert medications is fairly common in our country; though it is mostly done secretively and not entered in the case note of the patients. Regarding legal provision in our country, there is no mention about it in the MHA- 87 or in the MHCB. But the section 89 of the Indian Penal Code states that - "Nothing which is done in good faith for the benefit of a person under twelve years of age, or of unsound mind, by or by consent, either expressed or implied, of the guardian or other person having lawful charge of that person, is an offence by reason of any harm which it may cause, or be intended by the doer to cause or be known by the doer to be likely to cause to that person". This section provides immunity from criminal liability as the action of covert medications may be considered to be "acting in good faith", but the defence is yet to be tested in courts. ${ }^{21}$ In some western countries, there is provision of community treatment order which authorizes the community mental health team to carry out involuntary treatment in the community. But In India, there is no such legal provision either for community involuntary or covert treatment and both the MHA-87 (which is in force for the time being) and the recently introduced MHCB-2013 are silent about it. Kala advocates mainstreaming the community treatment orders and covert medication by families under specific circumstances into the mental health legislations. ${ }^{17}$ It is necessary that Indian Psychiatric Society takes cognizance of the matter and take necessary action by developing a guideline in this respect and suggesting to the government the necessary legal provisions which may be incorporated or introduced in this respect.

\section{CONCLUSION}

In the modern era of democratic principles, liberty and personal autonomy, informed consent is necessary in all medical interventions. In psychiatric practice, difficult situations may arise if the patient lacks the capacity to grant full informed consent and the medical intervention is carried out after obtaining proxy consent from his relatives/friends. We should be extra vigilant in such situations and must be conversant with the legal provisions and ethical issues. MHCB-2013 contains elaborate provisions about informed consent. ICMR prescribes strict guidelines in respect of informed consents in research projects and written consent is mandatory in all research projects.

\section{REFERENCES}

1. Lepping P. Consent in psychiatry - an ethical review, Psychiatric Bulletin, 2003; 27 : 285-89

2. Vikki, EL et al. Supporting patient autonomy : the importance of clinician-patient relationships. Journal of General Internal Medicine 2010 25, no. 7 : 741-745 


\section{Informed Consent in Psychiatric Practice}

3. Beauchamp, TL \& Childress, JF. Principles of Bio-Medical Ethics. 2009 6. New York : Oxford University Press.

4. Universal Declaration on Bioethics and Human Rights, adopted by UNESCO, October 2005, Available online at http://unesco.org. Last accessed on 16-09-15

5. WMA International Code of Medical Ethics, World Medical Association, available at http:/ / www.wma.net. last accessed on 16-09-2015

6. Samira Kohli v. Prabha Manchanda, Dr. \& Anr in Civil Appeal 1949 of 2004, CPJ 56 (SC) (2008) available at www. indiankanoon.org. Last accessed on 16-09-2015

7. Dyer AR \& Bloch S. Informed consent and the psychiatric patient, Journal of Medical Ethics, 1987; 13 :12-16

8. The Mental Health Care Bill 2013. Available from : $\underline{\mathrm{http}: / /}$ www.prsindia.org/billtrack/the-mental-health-care-bill2013-2864. [Last accessed on 16-09-15].

9. Indian Council of Medical Research. Ethical Guidelines for Biomedical Research on Human Participants. ICMR, 2006, Available from : http://icmr.nic.in/ethical_guidelines.pdf [Last accessed on 16-09-2015]

10. Suresh, BM. Revisiting Mental Health Legislation of India. Thesis submitted to the National Law School of India University, Bangalore for the award of Ph.D. Degree, July 2014.

11. Staden, CW \& Krüger, C Incapacity to give informed consent owing to mental disorder. JOURNAL OF MEDICAL ETHICS 2003; $29: 41-43$.
12. Applebaum PS \& Roth LH. Competency to consent to research: a psychiatric review. Arch Gen Psychiat, 1982; 39 : 951-8

13. The Mental Health Act 1987. Bare Act. Delhi Law House, Delhi, 1988.

14. Applebaum PS \& Grisso T. MacArthur Competence Assessment Tool for Clinical Research (MacCAT-CR), Sarasota : Professional Press; 2001

15. Tharyan P. Ethics in Psychiatric Research, in Forensic Psychiatry - Clinical Practice Guidelines in India, Indian Psychiatric Society, 2009 : 164-99

16. WMA Declaration of Helsinki - Ethical Principles for Medical Research Involving Human Subjects, available from www. wma.net. Last accessed on 16-05-15.

17. Kala AK. Covert medication; the last option : A case for taking it out of the closet and using it selectively, IndianJPsychiatry, 2012; $54: 257-65$

18. Latha KS. The Noncompliant Patient in Psychiatry : The Case For and Against Covert/Surreptitious Medication. Mens Sana Monogr 2010; 8 : 96-112.

19. The Royal College of Psychiatrists : College Statement on Covert Administration of Medicines. Psychiatr Bull 2004; 28 :385-6.

20. Sathyanarayana Rao TS, Kallilvayalil RA, Andrade C. Covert medication : Do means justify the ends? Indian J Psychiatry 2012; 54 : 203-5.

21. Sarin A. On covert medication: The issues involved. Indian J Psychiatry 2012; 54 : 271-2. 